\title{
The efficacy of microlearning in improving self-care capability: a systematic review of the literature
}

Objective: to determine the effectiveness of microlearning in improving an individual's capability to self-care.

Study design: Systematic review of the literature

Background: The routine adoption of health seeking self-care behaviours can prevent or delay the appearance of various lifestyle diseases including type 2 diabetes and cardiovascular disease. Microlearning delivers complex knowledge in fragments or bite-size 'nuggets' of information and has been applied as a novel intervention to improve individual's self-care capabilities. The aim of this research was to systematically review the literature to determine the effectiveness of microlearning in improving individual self-care capability.

Methods: A search was conducted on 15 July 2019 across 5 electronic bibliographic databases: EMBASE, MEDLINE, PsycINFO, CINAHL and Scopus. Randomised and non-randomised controlled trials, controlled before-after studies and interrupted time series studies, published between 1 January 1990 to 15 July 2019 and looking at individuals of all ages were included in the search. The search strategy included a keyword search and a string of "(modality) AND (learning) AND (micro)", which broadly described microlearning to cover all available articles that have used micro-format learning interventions. The search was combined with keywords and MeSH terms for self-care to identify studies of interests. Studies were screened by two reviewers independently and reported using a PRISMA flowchart. Data from included articles were extracted using Cochran Data Collection Form. Risk of bias was assessed using Version 2 of the Cochrane Risk-of-bias or Risk Of Bias In Non-Randomized Studies of Interventions.

Results: 1310 articles were identified in the initial search. A total of 26 manuscripts were included in the narrative synthesis after title and abstract and full text screening was performed by two reviewers. Outcomes of studies were categorized. A total of 23 studies measured cognitive level self-care capabilities changes, and $91 \%$ showed statistically significant improvements. Only 11 studies measured actual self-care behaviour changes, from which only $36 \%$ showed statistically significant results. From the 26 manuscripts included, 25 articles were evaluated as having moderate to high risk of bias.

Conclusion: Under certain conditions, or when combined with monitoring such as tracking daily medicine intake, microlearning can be effective in improving actual selfcare behaviours. Microlearning can also positively influence individuals' cognitive selfcare capabilities but was largely ineffective in triggering actual self-care behaviour change. More studies are needed to investigate the effectiveness of microlearning in improving self-care capabilities amongst the general population at scale. 


\section{Background}

The WHO report that nearly 41 million people die each year from non-communicable diseases (NCDs), equivalent to $71 \%$ of all deaths globally (1). The major risk factors associated with NCDs are unhealthy lifestyle choices and behaviours including tobacco use, physical inactivity, harmful use of alcohol and poor diets, which are modifiable by the adoption of health seeking self-care behaviours (1-4). Because self-care is "the ability of individuals, families and communities to promote health, prevent disease, and maintain health and to cope with illness and disability with or without the support of a health-care provider" (6), there is great interest in developing interventions that could improve the selfcare capabilities of individuals at scale to promote vitality in ageing, and to curb over-reliance on scarce national healthcare resources $(5,8-11)$

Innovative learning methods to improve population health such as internet-health (e-Health), mobile health (m-Health) and microlearning are rapidly gaining momentum as a preferred learning method outside of the formal education setting (13,17-20). In particular, microlearning which is as a person-centred learning intervention that delivers fragments of information that build up complex knowledge over time, is becoming increasingly well suited to help individuals learn about how to engage in self-care (14-16). Examples include public health awareness programmes, formal education, TV programming, and primary prevention and health screening campaigns $(9,10,12)$.

One of the main catalysts leading to the widespread use of microlearning is the evolution in individual learning style and behaviours, which have gradually become increasingly reliant on the use of digital technologies which allow individuals to learn at any place and at any time during their lifetime (21-23). Furthermore, as the human attention span has become shorter in the last two decades (26) thought to be due to the ubiquitous use and pervasiveness of bite-sized content used in television, mobile smartphone, tablets, personal computers and other technologies (27-29), it is now increasingly more important to frame information in small, easy to digest bite-sized nuggets of information that build up knowledge over time.

Microlearning is widely used in dentistry, pharmacy, epidemiology, psychiatry, and other health care related professional and higher education settings as an innovative way to stimulate student interest and to improve the bounds of learner thinking (17). Diverse microlearning modalities used both in class and as homework to stimulate students' learning enthusiasm include short video, audio and micro-assessment tools (35-38). Microlearning is being used in the training of healthcare workers to realise professional competencies and patient-care standards $(41,42)$. Medical students have reported being satisfied with this learning technique, describing that it improved teaching efficacy and understanding of learning content $(30,39,40)$.

Patient-facing microlearning initiatives in self-care have focused mainly on improving individual self-care capability (45-49). Most initiatives are concerned with improving pervasively low health literacy levels in the general population, whilst other initiatives aim to achieve a significant long-lasting positive effect on patients' health-seeking lifestyle choices and self-care behaviours (45-49). Microlearning-based campaigns on social media have been used to drive up health literacy levels $(5,19,45,50)$, whereas other applications promote healthy lifestyle by employing more interactive methods including gamification to gradually build up user interest, health literacy levels and self-care capabilities $(42,48)$. 
There exist a number of studies that use micro-format learning interventions to promote selfcare, but many do not identify their interventions as microlearning. Currently, there is only one systematic review on microlearning in a healthcare professional education setting, and no systematic review on the effect of microlearning in promoting individual self-care capability (17). The aim of this research is to systematically review the literature to determine the effectiveness of microlearning in improving individuals' capability to self-care.

\section{METHOD}

\section{Search Method}

The search was conducted on 15 July 2019 in 5 electronic bibliographic databases: EMBASE, MEDLINE, PsychINFO, CINAHL and SCOPUS. Articles published between 1 January 1990 and 15 July 2019 concerning all individuals were included. The strategy for microlearning search included a keyword search and Boolean terms, culminating in a string of "(modality) AND (learning) AND (micro)" search. Microlearning was therefore broadly described in order to cover all valuable articles that used micro-format learning interventions. The search for microlearning was then combined using Boolean terms with keywords and $\mathrm{MeSH}$ search terms for self-care to identify relevant studies. The detailed search query used can be found through this link: https://tinyurl.com/y9vjtbef

The protocol of the systematic review was published on National Institute for Health Research PROSPERO database (51). The link to PROPERO can be found here: https://tinyurl.com/ycy7gv2r

\section{Inclusion and exclusion criteria}

In order to identify relevant articles, the following definition of microlearning was used: "microlearning is a learning event that consists of a sequence of brief nuggets of information or 'micro-content' that builds up knowledge over a period of 6 months or less, and where each nugget of information is delivered in a single sitting of no longer than 10 minutes". Studies that did not test the effect of an intervention satisfying this definition were excluded. The detailed inclusion and exclusion criteria are listed in Table 1. The self-care capability outcomes and related outcome measurements used are listed in Table 2.

\section{Screening process \& risk of bias assessment}

Studies retrieved using the search strategy were screened independently by two reviewers using Covidence software. Reviewers were not blinded to the authors of the study or the journal where the study was published. Included studies were independently extracted by Reviewer 1 using 'Cochran Data collection form for intervention reviews: Randomised control trials (RCTs) and non-RCTs'. The data extraction sheet was reviewed by Reviewer 2 , and any disagreement of results was reviewed by a third reviewer and discussed between all three reviewers until a final decision was agreed by consensus.

Version 2 of the Cochrane risk-of-bias (RoB 2) tool was used to assess risk of bias in RCTs (52). Risk Of Bias In Non-Randomized Studies - of Interventions (ROBINS-I) was used for the rest of studies including non-RCTs, controlled before-after studies and Interrupted Time Series studies (53). Reviewer 1 independently assessed each included study based on related reporting guidelines. The assessment results were checked by Reviewer 2 . Any disagreement of results was checked by a third reviewer and discussed between all three reviewers until a decision was reached by consensus.

\section{RESULTS}


The database search resulted in the identification of 1310 articles. Fifteen duplicates were excluded, and the remains 1295 articles proceeded to title and abstract screening. Based on the specified exclusion criteria, 1052 records were deemed not relevant to the aim of the systematic review and subsequently excluded, leaving 243 potentially relevant articles for full text review.

During the full text review process, articles were excluded due to a combination of the following reasons: "intervention takes longer than 10 minutes in one sitting" $(n=66)$ or "Abstract Only" $(n=56)$. The rest of articles were excluded for reasons such as "Study does not state the duration of intervention" $(n=18)$, "Intervention performance testing only, including feasibility, usability, accessibility etc" ( $n=16)$, "Dissertation, review article, survey, editorial, case-study, case-control, cross-sectional, or poster" $(n=13)$, and "Microlearning intervention is part of a larger intervention and is not independently evaluated" $(n=12)$.

Thus, after reviewing the full text, 217 articles were excluded, resulting in a total of 26 articles that proceeded to the narrative analysis process. A Preferred Reporting Items for Systematic Reviews and Meta-Analyses (PRISMA) flow diagram (54) is shown in figure 1.

\section{Demographic data analysis}

According to the World Bank 2018 country classification, 23 out of $26(88.5 \%)$ articles were conducted in high-income countries, 2 in middle-income countries (8\%) and 1 in a lowincome country (4\%). Eight (31\%) articles had specially focused or inadvertently involved a high proportion of ethnic minority groups, such as non-Hispanic Black, African American, Hispanic, Thai-American, Caribbean American and Bangladeshi immigrants (49,55-61).

All studies $(n=26)$ targeted interventions on adults aged over 18 years old. Eight studies had participants with an average age of over 50 years old or over $(49,60,62-67)$. One study targeted teenagers (between 10 to 13 years old) who were taught about the detrimental health effects of smoking (66).

Sixteen articles (61.5\%) contained predominantly more female participants, however 8 of these studies were primarily concerned with women's health topics including cervical cancer, termination of pregnancy, maternal and child health, and interstitial cystitis, and therefore reasonably excluded male participation $(49,58,65,68-72)$. One study on the topic of healthy eating purposely excluded males (61). The remaining seven articles did not specify a reason for the higher proportion of female participants in the studies $(55,56,60,63,73-75)$. Five out of $26(19 \%)$ studies contained predominately more male participants due to the particularity of target groups such as prisoners, veterans, cardiovascular disease patients, etc. $(59,66,67,76,77)$. Only 4 studies had an almost equal distribution between gender groups $(57,62,64,78)$.

Study designs included twelve $(46 \%)$ randomized control trials, four $(15 \%)$ non-randomised control trials, two $(8 \%)$ controlled before-after studies, and eight $(31 \%)$ interrupted time series studies. Sixteen out of twenty-six articles (61\%) had a sample size over 100 participants. All articles had provided suitable statistical analysis and $P$ value to calculate statistical significance. Three articles did not provide information on ethics approval $(60,66,79)$. A detailed data extraction sheet is shown in Table 3. 
The included 26 studies used seven types of microlearning modalities in total including short video, pamphlet, website, application, e-newsletter, Facebook post and games. Microlearning interventions utilising short videos were most popular, accounting for 22 out of 26 studies (85\%).

\section{Measurement of self-care outcomes}

Included studies had a diverse self-care interest with the majority measuring more than one health outcome. Improvement in knowledge and health literacy was measured in 17 studies $(65 \%)$, whereas 16 studies $(62 \%)$ were concerned with improving mental wellbeing, selfawareness and agency (Table 3).

Fifteen studies (58\%) reported a statistically significant positive effect of microlearning on improving individuals' knowledge and health literacy, and eight studies (31\%) showed a statistically significant positive effect of microlearning on mental wellbeing, self-awareness \& agency improvement. All studies focusing on healthy eating, risk avoidance or mitigation, and good hygiene behaviour change reported that microlearning can positively impact an individuals' attitude towards adoption of a healthy lifestyle (61).

The majority of articles measured more than one health outcome. When considering all outcomes assessed, the results can be categorized as either being relevant to cognitive level self-care capability improvements or pertaining to self-care behaviour changes (Table 4). Nineteen articles (73\%) measured cognitive level self-care capabilities, including changes in attitude, knowledge, awareness, mood or stress changes $(69,74,75,77)$. The vast majority (89.5\%) of these articles reported statistically significant results. Eleven articles $(42 \%)$ tested actual self-care behaviour change following the intervention, such as attendance of cancer screening, weight loss or improvement in medical adherence. Seven out of 11 papers $(64 \%)$ reported an improvement in behaviour change following microlearning intervention but the effect was not statistically significant $(56,57,62,63,68,73,79)$. Only 4 out of 11 papers $(36 \%)$ reported a statistically significant improvement in self-care behaviours $(65,67-69)$ post microlearning intervention.

\section{One-time vs. sequential microlearning}

Ten out of 26 studies (38\%) used at least two segments of microlearning as their intervention, seven $(70 \%)$ of these showed a significant increase in individual's cognitive changes $(49,59,61,62,65,67,73-75,77)$ and two $(20 \%)$ of which found statistically significant change in behaviour changes $(65,67)$. Comparatively, of interventions that were only performed once $(n=16 ; 61 \%)$, ten studies $(63 \%)$ showed a significant impact on cognitive self-care outcomes, but only 2 studies showed a significant effect on complex behaviour change $(58,60,63,64,66,71,72,76,78,79)$.

\section{Intra comparison among different microlearning modalities}

There was insufficient evidence in the literature to generate a comparative analysis on the effectiveness of different microlearning modalities because the variation of microlearning modalities in the 26 included articles was small. Nevertheless, all website, application, game or social media interventions showed a significant improvement in at least one self-care outcome. However, no clear pattern or difference was found when comparing the effectiveness of short video and short handouts modalities, since the number of papers suggesting that short videos had a stronger effect was equal to the number of studies that did not show a difference between the handouts and video microlearning modalities. Equally, no pattern was found for the comparison between different narrative styles of short video contents. 


\section{Accessibility and adaptation of technology related with microlearning}

One article argued that insufficient knowledge about advanced technology or a lack of access to the internet may have influenced participant pursuit of health information online, especially in older age groups or participants from low-income and low-education groups (80).

Among the eight studies targeted primarily at the elderly, no participants reported technological difficulties whilst engaging with the microlearning modalities $(49,60,62-67)$. This may be because almost all of these studies used short videos as the main intervention, which are relatively user-friendly. The review of the literature suggests that poor digital literacy is not merely related to age, but more specifically to a personal unwillingness to learn or a feeling of insecurity or low confidence in using the technology by some groups (81-83). In fact, it is estimated that over $60 \%$ of elderly individuals have started using the internet to meet their needs $(82,84)$.

The findings also illustrate the existence of digital inequality (84)(85-89) which has previously been strongly correlated to social inequality, and is particularly pronounced in low socioeconomic groups with limited access to computer services (85-91). Three studies included in this systematic review excluded participants who did not have access to internet at home, which highlights the importance of internet access to the ability to engage with digital health interventions $(57,73,75)$. To prevent the growth of this disparity, interventions should ideally be designed with digital literacy and accessibility in mind, and universal coverage of digital resources should be accelerated $(90,91)$.

The majority of studies assessing cognitive self-care capabilities reported statistically significant improvements. This suggests that microlearning had a relatively strong ability to trigger cognitive level changes among individuals, including changes in attitude, knowledge, awareness, mood or stress changes $(69,74,75,77)$.

Nearly a third of included studies showed that microlearning did not have a statistically significant impact on behaviour change. While some articles showed improvements in individuals' attitude or knowledge towards behaviour change, no actual changes in behaviour were found $(56,57,62,73)$. Two interventions measured maternal and child health behaviour changes $(n=2)$, both of which reported statistically significant positive effects of microlearning on improving self-care behaviours among mothers $(68,69)$. Two other interventions included daily or weekly monitoring through the application platform or inpatient services in addition to microlearning, and yielded statistically significant improvement in self-care behaviour changes $(65,67)$. The observed changes in behaviours in these examples could be related to incentives (e.g. a mother's commitment to protect own health and the health of the child) and gamification or nudges in the case of wearable technologies for monitoring.

These findings suggest that the use of microlearning in certain scenarios, such as in maternal and child health or alongside monitoring, may be an effective way to promote a sustained adoption of desirable self-care behaviours. However, in majority of the cases, microlearning was considered ineffective in motivating individual behaviour change.

\section{Risk of bias assessment}

Of the 12 RCT studies included, 9 studies $(75 \%)$ were rated as having a moderate risk of bias, two studies (17\%) were at a serious bias, and only 1 study $(8 \%)$ was at a low risk of bias. A large proportion of moderate bias stemmed from the randomization, intervention and 
measurement categories. Four RCTs (33\%) did not clearly define the randomization protocol, whereas 3 RCTs (25\%) found significant differences in baseline values between intervention and control groups indicating a concern of bias in the randomization process. Seven RCTs (58\%) did not blind from the accessor's side resulting in bias in the intervention category and measurement category. Serious risks of bias were detected in three articles (25\%). Two studies (17\%) provided insufficient outcome data which made them vulnerable to bias of only revealing results of interests $(71,79)$, and one study $(8 \%)$ had a long followup period without controlling for external knowledge exposure, which made the measurement process highly vulnerable to bias (59).

From the 14 non-randomized control trails, interrupted time series and controlled before and after studies included, half $(n=7 ; 50 \%)$ were rated as having a moderate risk of bias and the other half as having a serious risk of bias. Because none of these articles applied blinding strategies, they were rated as having at least a moderate risk of bias in the measurement category, since participants may have had knowledge about the intervention, and this could affect their self-reported outcomes. None of the 14 non-RCTs applied proper controlling strategies to mitigate the impacts of confounders such as demographic factors, financial incentives in study participation or exposure to external knowledge other than intervention which could lead to a moderate to high risk of confounding bias.

\section{DISCUSSION}

\section{Key findings}

The definition used for microlearning, which emphasises multiple interventions over time, resulted in only two studies. We therefore decided to expand our analysis to include onetime learning interventions. The findings suggest micro-content sequence learning has a better effect than one-time microlearning interventions on influencing cognitive improvement. However, neither sequence learning nor one-time learning showed strong impact on influencing behaviour change.

The review showed that microlearning is only effective in improving self-care capabilities in the context of (i) promoting healthy eating, (ii) improving risk avoidance or mitigation skills, and (iii) promoting the adoption of good hygiene practices. However, microlearning was only partially effective in improving participant's mental wellbeing and self-awareness, knowledge and health literacy. Conversely, microlearning was not effective in improving the rational use of products and services among individuals, such as compliance. No statement can be made regarding the effect of microlearning on physical activity since none of the studies examined this particular self-care pillar. Table 5 shows the effectiveness of microlearning interventions in promoting self-care capability when mapped against the 7 pillars of self-care framework (7).

The majority of findings pertaining to improvements in cognitive self-care capabilities were statistically significant, suggesting that microlearning had a relatively strong ability to trigger cognitive level changes among individuals, including changes in attitude, knowledge, awareness, mood or stress changes $(69,74,75,77)$.

Nearly a third of studies showed that microlearning did not have a statistically significant impact on behaviour change. Some articles showed improvements in individuals' attitude or knowledge towards behaviour change, but no actual behaviour improvements were found $(56,57,62,73)$. Two interventions that measured maternal and child health behaviour 
changes reported statistically significant positive effects of microlearning on improving selfcare behaviours among mothers $(68,69)$. Two other interventions, which included monitoring via a digital smartphone app or inpatient services, yielded statistically significant improvement in self-care behaviour changes $(65,67)$. The observed changes in behaviours in these examples could be due to incentives (e.g. a mother's commitment to protect own health and the health of the child), gamification, prompts or nudges in the case of using wearables for monitoring. Overall, study findings showed that microlearning was largely ineffective in motivating a change in behaviour amongst individuals.

These findings need to be considered in light of the low to moderate quality of evidence examined when considering the effect of microlearning on various aspects relating to selfcare capabilities (94). Reasons include the small numbers of studies per outcome which limited interpretation of efficacy for the specific self-management support interventions investigated, and potential biases in the methodological conduct of studies including appropriate methods for blinding of investigators, participants and outcome assessors in behavioural intervention studies (95). The reasons for the marked heterogeneity for studies that reported self-care outcomes was consistent with other research as small studies have been shown to be more heterogeneous than larger studies and for other reasons including the variability related to the quality of the studies, characteristics of enrolled participants, and administered interventions (96).

\section{Strengths and limitations}

This is the first systematic review that looked at the effect of microlearning on improving individual's self-care capabilities. The wide search strategy captured a number of interventions that were not necessarily labelled as microlearning but would now be considered as such, and therefore strengthened the evidence base from which the systematic review drew on.

The main limitation of this study was related to the definition of microlearning provided which was relatively narrow and therefore did not consider complex interventions, or those interventions that mixed microlearning with clinical care. Failure to consider complex applications in the pre-designed inclusion and exclusion criteria may have accounted for a lack of diversity in the microlearning modalities included in this systematic review. The proposed definition, which required sequential interventions, rendered such narrow results that a decision was made to expand the analysis to include one-time learning intervention. Furthermore, a high proportion of studies were conducted in high-income countries. Although $8 \%$ of studies tried to tackle the effectiveness of microlearning among minority groups in a high-income country setting, the findings of these studies alone cannot confidently recommend the adoption and diffusion of microlearning interventions in lowincome country settings.

Further, there was an unequal distribution of gender in the included studies, which may cause strong bias in the study results of included papers. Although some articles applied suitable statistical methods to adjust for demographic factors when calculating their results, these demographic factors, especially gender, may still cause some concern of bias in the study findings.

\section{Implications for future research and policy makers}

In the context of promoting self-care capability, it has become clear that there is a need for a more accurate definition for microlearning (92). The absence of a definitive time-based duration-specified definition of microlearning means that researchers make value judgements on what is considered a "short time" or "micro-content" and the length of a single 
microlearning session in screened literatures therefore varied from 2 minutes to 90 minutes $(49,93)$. Future studies should strive to determine a precise definition for microlearning or to create a framework to standardise the design of microlearning.

Future studies should strive to control for the risk of biases by ensuring a near equal inclusion of gender groups, race groups or different income groups in the study population in order to render the findings more generalisable to a broader population.

\section{Conclusion}

This systematic review analysed the effectiveness of microlearning in improving self-care capability in individuals across all ages and settings. Microlearning can positively influence cognitive self-care capabilities including health literacy, knowledge development, attitude change and mental well-being. Microlearning did not always trigger self-care behaviour changes but can under certain situations be used to raise awareness about the importance of adopting personalised health seeking self-care strategies. More studies are needed to explore which microlearning modalities are most suited to effectively promote the wide adoption of health seeking self-care capabilities and behaviours.

Author statement: All authors (CW, MB, DR, SG, AM and AEO) provided substantial contributions to the conception, design, acquisition, and interpretation (CW, DR and $\mathrm{MB}$ ) of data study data and approved the final version of the paper. CW took the lead in planning the study with support from the co-authors and carried out the data analysis with support from $M B$ and $D R$. AEO is the guarantor.

Ethical approval: Not required for conducting a systematic review using medical databases.

Funding: Non received. The research was supported by the National Institute for Health Research (NIHR) Applied Research Collaboration (ARC) North West London. The views expressed are those of the authors and not necessarily those of the funder, the NHS, the NIHR or the Department of Health.

Competing interests: None. 


\section{REFERENCES}

1. Noncommunicable diseases [Internet]. [cited 2019 Jun 6]. Available from: https://www.who.int/news-room/fact-sheets/detail/noncommunicable-diseases

2. WHO | Risk factors. WHO [Internet]. 2019 [cited 2019 Jun 25]; Available from: https://www.who.int/gho/ncd/risk_factors/en/

3. Peters R, Ee N, Peters J, Beckett N, Booth A, Rockwood K, et al. Common risk factors for major noncommunicable disease, a systematic overview of reviews and commentary: the implied potential for targeted risk reduction. Ther Adv Chronic Dis. 2019;10:1-14.

4. AUSTENEL-OSTA1*, DAVID WEBBER2, SHAMINI GNANI1, RICKY BANARSEE1 DM, AZEEM MAJEED1 PS. The Self-Care Matrix: A unifying framework for self-care. Self care J [Internet]. 2010 [cited 2019 Aug 15]; Available from: https://selfcarejournal.com/article/the-self-care-matrix-aunifying-framework-for-self-care/

5. WHO. WHO consolidated Guideline on self-care interventions for health: sexual and reproductive health and rights. 2019.

6. World Health Organisation RO for S-EA. Self care for health:A handbook for community health workers \& volunteers. Who. 2013. 7-15 p.

7. The Seven Pillars of Self-Care - ISF [Internet]. [cited 2019 Jun 6]. Available from: http://isfglobal.org/practise-self-care/the-seven-pillars-of-self-care/

8. What is self-care? | Global Self-Care Federation [Internet]. [cited 2019 Jun 12]. Available from: https://www.selfcarefederation.org/what-is-self-care

9. Self Care Week [Internet]. Self Care Forum. [cited 2019 Jun 25]. Available from: http://www.selfcareforum.org/events/self-care-week/

10. International Self-Care Day - ISF [Internet]. [cited 2019 Jun 25]. Available from: http://isfglobal.org/international-self-care-day/

11. 12th WSMI Asia-Pacific Regional Conference \&amp; 4th APSMI General Assembly | Global Self-Care Federation [Internet]. [cited 2019 Jun 25]. Available from: https://www.selfcarefederation.org/news-events/12th-wsmi-asia-pacificregional-conference-4th-apsmi-general-assembly

12. Global Self-Care Federation | The Global Self-Care Federation is dedicated to a world where self-care increasingly contributes to better health and more sustainable healthcare systems. [Internet]. [cited 2019 Jun 7]. Available from: https://www.selfcarefederation.org/

13. Hug T, Lindner M, Bruck P. Microlearning: Emerging Concepts, Practices and Technologies after e-Learning. proceedings of Microlearning Conference 2005: learning \& working in new media. 2006. 224 p.

14. Meet Today's Healthcare Team: Patients + Doctors + Machines | Accenture [Internet]. [cited 2019 Jun 12]. Available from: https://www.accenture.com/gben/insight-new-2018-consumer-survey-digital-

health?c=psv_digitalhealthcodigitalhealthin_10306753\&n=spc_0618

15. Kummervold PE, Chronaki CE, Lausen B, Prokosch $\mathrm{H}-\mathrm{U}$, Rasmussen J, Santana S, et al. eHealth trends in Europe 2005-2007: a population-based survey. J Med Internet Res [Internet]. 2008 Nov 17 [cited 2019 Aug 15];10(4):e42. Available from: http://www.jmir.org/2008/4/e42/

16. WHO. Report of the third global survey on eHealth Global Observatory for eHealth Global diffusion of eHealth: Making universal health coverage achievable [Internet]. Geneva; 2016 [cited 2019 Aug 15]. Available from: http://apps.who.int/bookorders.

17. De Gagne JC, Woodward A, Park HK, Sun H, Yamane SS. Microlearning in 
health professions education. JBI Database Syst Rev Implement Reports. 2018;1.

18. So H-J, Roh S-Z, Oh J-E, Lee H, Lee J, Ji S. Adult Learners' Perspectives about Microlearning: Implications on the Design of Bite-Sized Content. 26Th Int Conf Comput Educ (Icce 2018). 2018;488-93.

19. Bruck PA, Motiwalla LF, Foerster F. Mobile learning with Micro-content: A framework and evaluation. BLED 2012 Proceedings. 2012;(2):527-43.

20. Möller $\mathrm{H}$, Mark $\mathrm{T}$, Hug T. Microlearning: an emerging field in science. Microlearning Conf 2006 [Internet]. 2007;(June):1-324. Available from: https://www.uibk.ac.at/iup/buch_pdfs/microlearning2006-druck.pdf

21. Bjork RA, Dunlosky J, Kornell N. Self-Regulated Learning: Beliefs, Techniques, and Illusions. Annu Rev Psychol [Internet]. 2013 Jan 3 [cited 2019 Aug 18];64(1):417-44.

Available from: http://www.annualreviews.org/doi/10.1146/annurev-psych-113011-143823

22. Rubenson K. Taking Stock of Lifelong learning in Canada: Insights from the Adult Education and Training Surveys. 2007;(21). Available from: http://en.copian.ca/library/research/takingstock_en/takingstock_en.pdf

23. Trilling B, Fadel C, Partnership for 21st Century Skills. 21st century skills: learning for life in our times. Jossey-Bass; 2009. 206 p.

24. Fox S. The Social Life of Health Information, 2011 | Pew Research Center's Internet \& American Life Project. 2011; Available from: http://www.pewinternet.org/Reports/2011/Social-Life-of-Health-Info.aspx

25. The social life of health information [Internet]. Pew Research Center. 2014 [cited 2019 Nov 2]. Available from: https://www.pewresearch.org/facttank/2014/01/15/the-social-life-of-health-information/

26. Rudolf B. Present-Day Corporate Communication A Practice-Oriented, State-ofthe-Art Guide. Springer [Internet]. 2018 [cited 2019 Nov 2];18. Available from: https://doi.org/10.1007/978-981-13-0402-6

27. Hayles NK. Hyper and Deep Attention: The Generational Divide in Cognitive Modes [Internet]. Profession. Modern Language Association; [cited 2019 May 27]. p. 187-99. Available from: https://www.jstor.org/stable/25595866

28. Lodge JM, Harrison WJ. Focus: Attention Science: The Role of Attention in Learning in the Digital Age. Yale J Biol Med. 2019;92(1):21.

29. Canada M. Attention spans. 2015.

30. Buchem I. Microlearning: a strategy for ongoing professional development Microcontent and Microlearning. eLearningpapers. 2010;(September 2010):115.

31. Ahson S, Ilyas M. Mobile Web 2.0 : developing and delivering services to mobile devices. Auerbach Publications; 2011.

32. Kovachev D, Cao Y, Klamma R, Jarke M. Learn-as-you-go: New Ways of CloudBased Micro-learning for the Mobile Web. In Springer, Berlin, Heidelberg; 2011 [cited 2019 May 10]. p. 51-61. Available from: http://link.springer.com/10.1007/978-3-642-25813-8_6

33. Hug $\mathrm{T}$, Friesen $\mathrm{N}$. Outline of a Microlearning agenda. eLearning Pap. 2009;16(September):1-13.

34. Theo $\mathrm{H}$. Microlearning as a Challenge for Instructional Design. In: Didactics of Microlearning. 2007. p. 98-125.

35. Oermann MH, De Gagne JC, Phillips BC, editors. Teaching in Nursing and Role of the Educator [Internet]. New York, NY: Springer Publishing Company; 2017 [cited 2019 Jun 5]. Available from: 
http://connect.springerpub.com/lookup/doi/10.1891/9780826140142

36. Yang Y, You J, Wu J, Hu C, Shao L. The Effect of Microteaching Combined with the BOPPPS Model on Dental Materials Education for Predoctoral Dental Students. J Dent Educ. 2019 May 11;83(5):567-74.

37. Nikou SA, Economides S.A.; ORCID: http://orcid.org/0000-0001-9941-2125, Economides, A.A.; ORCID: http://orcid.org/0000-0001-8056-1024 AAAI-O http://orcid. org/Niko. Mobile-based micro-learning and assessment: Impact on learning performance and motivation of high school students. Ahmed Babaali, Bruck, Buchem, Bundovski, Burgers, Chee, Chen, Ciampa, Coakley, Cohen, Csikszentmihalyi, de-Marcos, Deci, Deci, Epstein, Fan, Fyfe, Gikandi, Hagger, Harfitt, Hartnett, Hauk, Huang, Hug, Hwang, Hwang, Hwang, Hwang, Katz, Katz, Kearney, Kell B, editor. J Comput Assist Learn [Internet]. 2018;No-Specified. Available from: http://ovidsp.ovid.com/ovidweb.cgi?T=JS\&PAGE=reference\&D=psyc14\&NEW $\mathrm{S}=\mathrm{N} \& A \mathrm{~N}=2018-06420-001$

38. Sheng M, Shah P, Choi JM, Gillis E, Katz SI, Simpson SA, et al. PatientCentered and Specialty-Specific Case Work-Up: An Effective Method for Teaching Appropriateness of Imaging to Medical Students. Acad Radiol [Internet]. 2019;26(6):846-50. Available from: http://ovidsp.ovid.com/ovidweb.cgi?T=JS\&PAGE=reference\&D=prem\&NEWS $=$ $\mathrm{N} \& A \mathrm{~N}=30737076$

39. Curran V, Matthews L, Fleet L, Simmons K, Gustafson D, MEd P, et al. A Review of Digital, Social, and Mobile Technologies in Health Professional Education. J Contin Educ Heal Prof [Internet]. 2017;37(3):195-206. Available from: http://ovidsp.ovid.com/ovidweb.cgi?T=JS\&PAGE=reference\&D=yrovfts\&NEWS $=\mathrm{N} \& \mathrm{AN}=00005141-201703730-00008$

40. Torre DM, Simpson D, Sebastian JL, Elnicki DM. Learning/Feedback Activities and High-Quality Teaching: Perceptions of Third-Year Medical Students during an Inpatient Rotation. Barzansky Barzansky, Barzansky, Blumenthal, Bolognia, Branch, Elliot, Elnicki, Elnicki, Elnicki, Ende, Ende, Garrett, Goroll, Griffith, Griffith, Hewson, Hunter, Irby, Kogan, Kroenke, LaCombe, Lake, Litzelmaii, Magadan, Miller, Nordgren, Norgaard, Pangar B, editor. Acad Med [Internet]. 2005;80(10):950-4. Available

from: http://ovidsp.ovid.com/ovidweb.cgi?T=JS\&PAGE=reference\&D=psyc4\&NEWS $=\mathrm{N} \& \mathrm{AN}=2005-11768-005$

41. Gross B, Rusin L, Kiesewetter J, Zottmann JM, Fischer MR, Pruckner S, et al. Microlearning for patient safety: Crew resource management training in 15minutes. PLoS One [Internet]. 2019;14(3):e0213178. Available from: http://ovidsp.ovid.com/ovidweb.cgi?T=JS\&PAGE=reference\&D=prem\&NEWS $=$ $\mathrm{N} \& \mathrm{AN}=30845165$

42. Orwoll B, Diane S, Henry D, Tsang L, Chu K, Meer C, et al. Gamification and Microlearning for Engagement With Quality Improvement (GAMEQI): A Bundled Digital Intervention for the Prevention of Central Line-Associated Bloodstream Infection. Am J Med Qual [Internet]. 2018;33(1):21-9. Available from: http://ovidsp.ovid.com/ovidweb.cgi?T=JS\&PAGE=reference\&D=prem\&NEWS= $\mathrm{N} \& A \mathrm{~N}=28482161$

43. Nayton K, Fielding E, Brooks D, Graham FA, Beattie Deborah; ORCID: http://orcid.org/0000-0003-4902-0654, Beattie, Elizabeth; ORCID: http://orcid.org/0000-0002-9779-0605 EAl-O http://orcid. org/Brook. Development of an education program to improve care of patients with dementia 
in an acute care setting. Beer Dc Bellis, Dewing, Draper, Eggenberger, Ervin, Featherstone, Ferri, Forsetlund, Gandesha, Grimshaw, Illes, Jones, Kirkpatrick, Lintern, Loyola, Millard, Moyle, Mukadem, Mukhopadhyay, Royer, Smyth, Spector, Thelen, Travers, Travers, While, Yamnill B, editor. J Contin Educ Nurs [Internet]. 2014;45(12):552-8. Available from: http://ovidsp.ovid.com/ovidweb.cgi?T=JS\&PAGE=reference\&D=psyc11\&NEW $\mathrm{S}=\mathrm{N} \& A N=2014-56124-007$

44. Dunivin D, Southwell G. Psychopharmacology Training in Psychology Internships: A Brief Curriculum. Prof Psychol Res Pr [Internet]. 2000;31(6):6104. Available from: http://ovidsp.ovid.com/ovidweb.cgi?T=JS\&PAGE=reference\&D=yrovftd\&NEW $\mathrm{S}=\mathrm{N} \& \mathrm{AN}=00001326-200012000-00004$

45. Bricon-Souf N, Leroy N, Renard JM. Augmented notebooks for pervasive learning in medical practice. Stud Health Technol Inform. 2010;160(PART 1):634-8.

46. Choi J, PhD MPH. Improving Discharge Education Using Pictographs. Rehabil Nurs [Internet]. 2013;38(5):240-6. Available from: http://ovidsp.ovid.com/ovidweb.cgi?T=JS\&PAGE=reference\&D=yrovfto\&NEW $\mathrm{S}=\mathrm{N} \& A \mathrm{~N}=00006939-201309000-00005$

47. Halbach T, Solheim I, Ytrehus S, Schulz T. A Mobile Application for Supporting Dementia Relatives: A Case Study. Stud Health Technol Inform. 2018;256:83946.

48. Simons LPA, Foerster F, Bruck PA, Motiwalla L, Jonker CM. Microlearning mApp raises health competence: hybrid service design. Health Technol (Berl). 2015;5(1):35-43.

49. Davis SA, Carpenter D, Cummings DM, Lee C, Blalock SJ, Scott JE, et al. Patient adoption of an internet based diabetes medication tool to improve adherence: A pilot study. Carpenter Davis, DeWalt, Fisher, Horne, Huang, Kalichman, King, Kroenke, Mann, Mayberry, McDonald, Morisky, Nau, Onwudiwe, Osborn, Osterberg, Seligman, Simons, Sleath, Smith, Valdez, Zickuhr C, editor. Patient Educ Couns [Internet]. 2017;100(1):174-8. Available from: http://dx.doi.org/10.1016/j.pec.2016.07.024

50. Kovacs G. FeedLearn: Using Facebook Feeds for Microlearning. [cited 2019 Jun 7]; Available from: http://dx.doi.org/10.1145/2702613.2732775

51. El-Osta A, Bakhet M, Wang C, Roberts D, Gnani S. The effect of microlearning in improving an individual's capability to self-care [Internet]. PROSPERO. 2019 [cited 2019 Nov 1]. Available from: https://www.crd.york.ac.uk/prospero/display_record.php?ID=CRD4201914649 5

52. The Cochrane Collaboration. RoB 2: A revised Cochrane risk-of-bias tool for randomized trials. 2019;(July). Available from: https://methods.cochrane.org/bias/resources/rob-2-revised-cochrane-risk-biastool-randomized-trials

53. (NICE)NICE UNI for H and CE. The Risk Of Bias In Non-randomized Studies of Interventions (ROBINS-I) assessment tool ROBINS-I tool (Stage I): At protocol stage. 2006;77-96.

54. Moher D, Liberati A, Tetzlaff J, Altman DG, Group TP. Preferred Reporting Items for Systematic Reviews and Meta-Analyses: The PRISMA Statement. PLoS Med [Internet]. 2009 Jul 21 [cited 2019 Aug 18];6(7):e1000097. Available from: https://dx.plos.org/10.1371/journal.pmed.1000097 
55. Guralnick AS, Balachandran JS, Szutenbach S, Adley K, Emami L, Mohammadi $\mathrm{M}$, et al. Educational video to improve CPAP use in patients with obstructive sleep apnoea at risk for poor adherence: A randomised controlled trial. Thorax [Internet]. 2017;72(12):1132-9. Available from: http://thorax.bmj.com/

56. C. H, S. W, I. A, M.I. A, H. K, J.R. M, et al. Evaluation of educational videos to increase skin cancer risk awareness and sun-safe behaviors among adult Hispanics. Andreeva Collins, Frosch, Gagliano, Gimeno-Garcia, Hernandez, $\mathrm{Hu}, \mathrm{Hu}$, Koroukian, Krouse, Ma, Pollitt, Prochaska, Snyder-Ramos, Sobel, Sweat, Tucker, Tuong, We, Yancey A, editor. J Cancer Educ [Internet]. 2014;29(3):563-9. Available from: http://ovidsp.ovid.com/ovidweb.cgi?T=JS\&PAGE=reference\&D=psyc11\&NEW $\mathrm{S}=\mathrm{N} \& A N=2016-24272-026$

57. Roman CJ, Guan X, Barnholtz-Sloan JS, Xu J, Bordeaux JS. A trial online educational melanoma program aimed at the hispanic population improves knowledge and behaviors. Dermatologic Surg. 2016;42(5):672-6.

58. Love GD, Mouttapa M, Tanjasiri SP, G.D. L, M. M, Love GD, et al. Everybody's talking: Using entertainment-education video to reduce barriers to discussion of cervical cancer screening among Thai women. Adams Borrayo, Coughlin, Horton, Jibaja, Lazarsfeld, Love, Love, Mead, Montano, Nariman, Papa, Papa, Piotrow, Rogers, Rogers, Singhal, Singhal, Taylor, Taylor, Tsui, Valente B, editor. Health Educ Res [Internet]. 2009;24(5):829-38. Available from: http://ovidsp.ovid.com/ovidweb.cgi?T=JS\&PAGE=reference\&D=psyc6\&NEWS $=\mathrm{N} \& A \mathrm{~N}=2009-16320-010$

59. Houston TKTK, Fix GM, Shimada SLSL, Long JAJA, Gordon HSHS, Pope C, et al. African American Veterans Storytelling: A Multisite Randomized Trial to Improve Hypertension. Med Care [Internet]. 2017;55 Suppl 9(9):S50-8. Available from: http://ovidsp.ovid.com/ovidweb.cgi?T=JS\&PAGE=reference\&D=med13\&NEW $\mathrm{S}=\mathrm{N} \& \mathrm{AN}=28806366$

60. Latif S, Ahmed I, Amin MS, Syed I, Ahmede N. Exploring the potential impact of health promotion videos as a low cost intervention to reduce health inequalities: A pilot before and after study on Bangladeshis in Inner-city London. London $\mathrm{J}$ Prim Care (Abingdon) [Internet]. 2016;8(4):66-71. Available from: https://www.scopus.com/inward/record.uri?eid=2-s2.0-

84983554939\&doi=10.1080\%2F17571472.2016.1208382\&partnerID=40\&md5 $=332 \mathrm{baac} 114 \mathrm{eb} 7 \mathrm{e} 8 \mathrm{c} 671$ ef2fa7a7bbba9

61. Thomas NM. Caribbean (English-Speaking) Women in the United States: Cooking for Diabetes Prevention and Management. J Immigr Minor Heal [Internet]. 2018;20(4):1025-8. Available from: http://ovidsp.ovid.com/ovidweb.cgi?T=JS\&PAGE=reference\&D=emexb\&NEW $\mathrm{S}=\mathrm{N} \& A \mathrm{~N}=625682456$

62. Ferguson $M$, Brandreth $M$, Brassington $W$, Leighton $P$, Wharrad $H, M$. $F$, et al. A Randomized Controlled Trial to Evaluate the Benefits of a Multimedia Educational Program for First-Time Hearing Aid Users. Ear Hear [Internet]. 2016;37(2):123-36. Available from: http://ovidsp.ovid.com/ovidweb.cgi?T=JS\&PAGE=reference\&D=med12\&NEW $\mathrm{S}=\mathrm{N} \& \mathrm{AN}=26565785$

63. L.K. L, D. M, D.J. R, R.D. H, A.M. L, B. S, et al. Randomized controlled trial of storytelling compared to a personal risk tool intervention on colorectal cancer screening in low-income patients. Am J Heal Promot [Internet]. 2015;30(2):e59_ 
70.

Available

from:

http://ovidsp.ovid.com/ovidweb.cgi?T=JS\&PAGE=reference\&D=emed16\&NEW $\mathrm{S}=\mathrm{N} \& \mathrm{AN}=616510179$

64. Denny MC, Vahidy F, Vu KYT, Sharrief AZ, Savitz SI. Video-based educational intervention associated with improved stroke literacy, selfefficacy, and patient satisfaction. PLoS One. 2017;12(3):1-12.

65. Lee MH, Wu HC, Tseng CM, Ko TL, Weng TJ, Chen YF. Health Education and Symptom Flare Management Using a Video-based m-Health System for Caring Women With IC/BPS. Urology [Internet]. 2018;119:62-9. Available from: https://doi.org/10.1016/j.urology.2018.05.027

66. Mahler HI, Kulik JA. Effects of preparatory videotapes on self-efficacy beliefs and recovery from coronary bypass surgery. Ann Behav Med [Internet]. 1998;20(1):39-46. Available

from: http://ovidsp.ovid.com/ovidweb.cgi?T=JS\&PAGE=reference\&D=med4\&NEWS $=\mathrm{N} \& \mathrm{AN}=9755351$

67. Yeh $\mathrm{M}-\mathrm{L}$, Chen $\mathrm{H}-\mathrm{H}$, Liu P-H. Effects of multimedia with printed nursing guide in education on self-efficacy and functional activity and hospitalization in patients with hip replacement. Altizer Butler, Cahill, Daltroy, Davidson, Enloe, Flapan, Gammon, Gillespie, Haines, Heaton, Hong, Hough, Hsu, Hsueh, Jette, Kurlowicz, Lorig, Oetker-Black, Orr, Palmer, Pellino, Santavirta, Scherer, Shelton, Shields, Spalding, Tsai, Waltz, Weingarten, W B, editor. Patient Educ Couns [Internet]. 2005;57(2):217-24. Available from: http://ovidsp.ovid.com/ovidweb.cgi?T=JS\&PAGE=reference\&D=psyc4\&NEWS $=\mathrm{N} \& \mathrm{AN}=2005-07089-011$

68. Hughes BL, Gans KM, Raker C, Hipolito ER, Rouse DJ, B.L. H, et al. A brief prenatal intervention of behavioral change to reduce the risk of maternal cytomegalovirus: A randomized controlled trial. Obstet Gynecol [Internet]. 2017;130(4):726-34. Available from: http://ovidsp.ovid.com/ovidweb.cgi?T=JS\&PAGE=reference\&D=med13\&NEW $\mathrm{S}=\mathrm{N} \& \mathrm{AN}=28885428$

69. Clifford, H., Johnson, Newell, Brown, C., Battistutta D. When can oral health education begin? Relative effectiveness of three oral health education strategies starting pre- partum. Community Dent Heal DOI. 2012;(29):162-7.

70. Davidson AS, Whitaker AK, Martins SL, Hill B, Kuhn C, Hagbom-Ma C, et al. Impact of a theory-based video on initiation of long-acting reversible contraception after abortion. Am J Obstet Gynecol [Internet]. 2015;212(3):310.e1-7. Available from: http://ovidsp.ovid.com/ovidweb.cgi?T=JS\&PAGE=reference\&D=med11\&NEW $\mathrm{S}=\mathrm{N} \& \mathrm{AN}=25265403$

71. Price SM, Bonilla E, Zador P, Levis DM, Kilgo CL, Cannon MJ. Educating women about congenital cytomegalovirus: assessment of health education materials through a web-based survey. BMC Womens Health [Internet]. $2014 ; 14: 144$. Available from: http://ovidsp.ovid.com/ovidweb.cgi?T=JS\&PAGE=reference\&D=med10\&NEW $\mathrm{S}=\mathrm{N} \& A \mathrm{~N}=25433837$

72. Lamb RLB, Ramos Jaraba SM, Graciano Tangarife V, Garcés-Palacio IC. Evaluation of Entertainment Education Strategies to Promote Cervical Cancer Screening and Knowledge in Colombian Women. $J$ Cancer Educ. 2018;33(5):1094-101.

73. West DS, Monroe CM, Turner-McGrievy G, Sundstrom B, Larsen C, Magradey 
$\mathrm{K}$, et al. A Technology-Mediated Behavioral Weight Gain Prevention Intervention for College Students: Controlled, Quasi-Experimental Study. J Med Internet Res. 2016;18(6):e133.

74. Drozd F, Raeder S, Kraft P, Bjørkli CA. Multilevel growth curve analyses of treatment effects of a Web-based intervention for stress reduction: randomized controlled trial. J Med Internet Res. 2013 Apr 22;15(4):e84.

75. Parisod H, Pakarinen A, Axelin A, Löyttyniemi E, Smed J, Salanterä S. Feasibility of mobile health game "Fume" in supporting tobacco-related health literacy among early adolescents: A three-armed cluster randomized design. Int $\mathrm{J}$ Med Inform [Internet]. 2018;113(July 2017):26-37. Available from: https://doi.org/10.1016/j.ijmedinf.2018.02.013

76. J.A. L, H.I.S. L, A.Q. T, A. M, J.G. C, J. R, et al. Brief video intervention to improve attitudes throughout medications for opioid use disorder in a correctional setting. J Subst Abuse Treat [Internet]. 2019;104(June):28-33. Available from: http://www.elsevier.com/locate/jsat

77. Meinlschmidt G, Lee J-HH, Stalujanis E, Belardi A, Oh M, Jung EK, et al. Smartphone-based psychotherapeutic micro-interventions to improve mood in a real-world setting. Ahmedani Andersson, Andersson, Asselbergs, Bakker, Bates, Baumeister, Ben Khelil, Ben-Zeev, Ben-Zeev, Bower, Bradley, Brake, Choi, Cipresso, Clough, Collins, Collins, Cuijpers, de Charms, Dinakar, Donker, Ebert, Ehrenreich, Faul, Fox, Frank, Franklin, Fr A, editor. Front Psychol [Internet]. 2016;7(JUL). Available from: http://ovidsp.ovid.com/ovidweb.cgi?T=JS\&PAGE=reference\&D=psyc13\&NEW $\mathrm{S}=\mathrm{N} \& A \mathrm{~N}=2016-40692-001$

78. Patel PH, Bibee K, Lim G, Malik SM, Wu C, Pugliano-Mauro M. Evaluating Retention of Skin Cancer Education in Kidney Transplant Recipients Reveals a Window of Opportunity for Re-education. Transplant Proc. 2017;49(6):1318-24.

79. Y.S. R, L.B. S, M.A. H, Rimal R.N. AO - Ranjit YS. O http://orcid. org/000.0002-4361-7508, Ranjit YS, Snyder LB, et al. Self-Determination Theory and Risk Behavior in a Collectivistic Society: Preventing Reckless Driving in Urban Nepal. J Health Commun [Internet]. 2017;22(8):672-81. Available from: http://ovidsp.ovid.com/ovidweb.cgi?T=JS\&PAGE=reference\&D=medc\&NEWS $=\mathrm{N} \& \mathrm{AN}=28753075$

80. Jensen JD, King AJ, Davis LA, Guntzviller LM. Utilization of Internet Technology by Low-Income Adults. J Aging Health. 2010 Sep 21;22(6):804-26.

81. Nichols KL. OPTIMIZING THE SILVER COLLAR WORKER: IN THE SHOES OF THE OLDER EMPLOYEE. Int J Organ Theory Behav [Internet]. 2001 Jul 31 [cited 2019 Aug 18];4(3-4):225-46. Available from: http://www.tandfonline.com/doi/abs/10.1081/OTB-100105403

82. Githens RP. Scholarly Commons Older adults and e-learning: Opportunities and Barriers [Internet]. 2007 [cited 2019 Aug 18]. Available from: https://scholarlycommons.pacific.edu/ed-facarticles

83. Safi S, Thiessen T, SchmailzI KJ. Acceptance and Resistance of New Digital Technologies in Medicine: Qualitative Study. JMIR Res Protoc. 2018;7(12):e11072.

84. Chiu C-J, Liu C-W. Understanding Older Adult's Technology Adoption and Withdrawal for Elderly Care and Education: Mixed Method Analysis from National Survey. J Med Internet Res. 2017;19(11):e374.

85. Robinson L, Cotten SR, Ono H, Quan-Haase A, Mesch G, Chen W, et al. Digital inequalities and why they matter. Information, Commun Soc [Internet]. 2015 May 
4 [cited 2019 Aug 18];18(5):569-82. Available from: http://www.tandfonline.com/doi/abs/10.1080/1369118X.2015.1012532

86. Po- JJ, Hsieh A, Rai A, Keil M. UNDERSTANDING DIGITAL INEQUALITY: COMPARING CONTINUED USE BEHAVIORAL MODELS OF THE SOCIOECONOMICALLY ADVANTAGED AND DISADVANTAGED 1 [Internet]. Vol. 32, Understanding Digital Inequality MIS Quarterly. 2008 [cited 2019 Aug 18]. Available from: https://pdfs.semanticscholar.org/b6c4/da059beeca2a9bf5c38b18d9c57b85480 fef.pdf? ga=2.268918833.1908200540.1566077495-1924327834.1558962206

87. Araque JC, Maiden RP, Bravo N, Estrada I, Evans R, Hubchik K, et al. Computer usage and access in low-income urban communities. Com Puter Hum Behav [Internet]. 2013 [cited 2019 Aug 18];29. Available from: https://pdf.sciencedirectassets.com/271802/1-s2.0-S0747563213X00032/1s2.0-S0747563213000356/main.pdf?X-Amz-Security-

Token=AgoJb3JpZ2luX2VjEOT\%2F\%2F\%2F\%2F\%2F\%2F\%2F\%2F\%2F\%2F wEaCXVzLWVhc3QtMSJHMEUCICI1IEfnqHJGkEHBY40XWoQGeCx7Px\%2B hNx4znPQIH5jTAiEA7m22vl\%2Fd

88. OECD. UNDERSTANDING THE DIGITAL DIVIDE [Internet]. 2001 [cited 2019 Aug 18]. Available from: http://www.oecd.org/internet/ieconomy/1888451.pdf

89. Papastergiou S, Polemi D, Douligeris C. Next Generation Society. Technological and Legal Issues. Lect Notes Inst Comput Sci Soc Telecommun Eng [Internet]. 2010;26(August 2015):421-30. Available from: http://www.scopus.com/inward/record.url?eid=2-s2.084885892505\&partnerID=tZOtx3y1

90. Latulippe K, Hamel C, Giroux D. Social Health Inequalities and eHealth: A Literature Review With Qualitative Synthesis of Theoretical and Empirical Studies. J Med Internet Res. 2017;19(4):e136.

91. Neter E, Brainin E. eHealth literacy: extending the digital divide to the realm of health information. J Med Internet Res [Internet]. 2012 Jan 27 [cited 2019 Aug 18];14(1):e19. Available from: http://www.jmir.org/2012/1/e19/

92. Torgerson $\mathrm{C}$. The microlearning guide to microlearning. 2016. $181 \mathrm{p}$.

93. Kuon E, Dahm JB, Robinson DM, Empen K, Gunther M, Wucherer W. Radiationreducing planning of cardiac catheterisation. Z Kardiol [Internet]. 2005;94(10):663-73. Available from: http://ovidsp.ovid.com/ovidweb.cgi?T=JS\&PAGE=reference\&D=med5\&NEWS $=\mathrm{N} \& \mathrm{AN}=16200481$

94. Zmbudzi E, Lo C, Misso ML, Ranasinha S, Kerr PG, Teede HJ, et al. Effectiveness of self-management support interventions for people with comorbid diabetes and chronic kidney disease: a systematic review and meta-analysis. Syst Rev. 2018;7(1):84-.

95. IntHout J, loannidis JP, Borm GF, Goeman JJ. Small studies are more heterogeneous than large ones: a meta-meta-analysis. J Clin Epidemiol. 2015;68(8):860-869. doi: 10.1016/j.jclinepi.2015.03.017.

96. De Gagne JC, Park HK, Hall K, Woodward A, Yamane S, Kim SS. Microlearning in Health Professions Education: Scoping Review. JMIR Med Educ. 2019;5(2):e13997. Published 2019 Jul 23. doi:10.2196/13997 